\title{
Ensino e aprendizagem em Psicologia Social no ensino remoto emergencial
}

\author{
Docencia y aprendizaje en Psicología Social en educación remota de emergencia
}

\section{Teaching and learning in Social Psychology in emergency remote education}

\author{
Moises Romanini \\ Universidade Federal do Rio Grande do Sul (UFRGS), Rio Grande do Sul - RS/Brasil \\ ORCID: 0000-0003-3288-4763 \\ E-mail: moisesromanini@yahoo.com.br
}

\begin{abstract}
Resumo
A pandemia do novo coronavírus, diante da necessidade de distanciamento social, trouxe para as universidades o desafio do Ensino Remoto Emergencial. O objetivo deste artigo é o de refletir sobre as experiências construídas ao longo de um semestre na disciplina de Psicologia Social, na modalidade remota de ensino. Inspirado na pedagogia engajada de bell hooks, refletimos sobre três ensinamentos desta experiência: a pandemia não é democrática - a negação do direito à educação; entendendo o ERE e os limites da aula expositiva - conversação e compartilhamento de histórias; e aprendizagem colaborativa online, comunidade de aprendizagem e pensamento crítico. Ressaltamos que a utilização das tecnologias digitais de informação e comunicação possibilitou a construção de aprendizagens significativas, mas temos como desafios a apropriação dessas metodologias mais participativas no modelo presencial e o acompanhamento e inclusão de estudantes que, por razões diversas, não conseguiram se vincular ao semestre remoto. Provavelmente as dificuldades vividas por esses/as estudantes já existissem, mas as condições sociais, culturais e econômicas que sustentam as desigualdades sociais se tornaram mais visíveis com a pandemia, e isso deve nos sensibilizar quando do retorno presencial das aulas.
\end{abstract}

Palavras-chaves: Psicologia Social; Tecnologia educacional; Métodos de ensino; Igualdade social; Pandemia.

\section{Resumen}

La pandemia del nuevo coronavirus, dada la necesidad de distanciamiento social, trajo el desafío de la Educación Remota de Emergencia a las universidades. El propósito de este artículo es reflexionar sobre las experiencias construidas a lo largo de un semestre en la disciplina de Psicología Social, en la modalidad de enseñanza a distancia. Inspirado en la pedagogía comprometida de bell hooks, reflexionamos sobre tres enseñanzas de esta experiencia: la pandemia no es democrática - la negación del derecho a la educación; comprender el ERE y los límites de la conferencia: conversación e intercambio de historias; y el aprendizaje colaborativo en línea, la comunidad de aprendizaje y el pensamiento crítico. Destacamos que el uso de tecnologías de la información y la comunicación digitales permitió la construcción de aprendizajes significativos, pero tenemos como desafíos la apropiación de estas metodologías más participativas en el modelo presencial y el seguimiento e inclusión de estudiantes que, por diversas razones, no pudieron vincularse al semestre remoto. Probablemente las dificultades vividas por estos estudiantes ya existían, pero las condiciones sociales, culturales y económicas que sustentan las desigualdades sociales se han vuelto más visibles con la pandemia, y esto debería hacernos conscientes cuando volvamos a clases en persona.

Palabras clave: Psicología Social; Tecnologia educacional; Métodos de enseñanza; Igualdad social; pandemia.
Abstract
The pandemic of the new coronavirus, given the need for social distance, brought the challenge of Emergency Remote Education to universities. The purpose of this article is to reflect on the experiences built over a semester in the discipline of Social Psychology, in the remote mode of teaching. Inspired by the engaged pedagogy of bell hooks, we reflected on three teachings from this experience: the pandemic is not democratic - the denial of the right to education; understanding the ERE and the limits of the lecture - conversation and sharing stories; and collaborative online learning, the learning community and critical thinking. We emphasize that the use of digital information and communication technologies enabled the construction of significant learning, but we have as challenges the appropriation of these more participatory methodologies in the face-to- face model and the monitoring and inclusion of students 
who, for various reasons, were unable to link to the remote semester. Probably the difficulties experienced by these students already existed, but the social, cultural and economic conditions that support social inequalities have become more visible with the pandemic, and this should make us aware when we return to classes in person.

Keywords: Social Psychology; Educational technology; Teaching methods; Social equality; Pandemic.

\section{Introdução - o retorno às aulas e a suspensão das atividades presenciais ${ }^{1}$}

Março de 2020, voltávamos a mais um semestre letivo na universidade. $\mathrm{Na}$ região central da cidade, intenso movimento de pedestres, transportes coletivos e carros. Corredores e salas de aulas dos prédios da universidade sendo ocupados por estudantes, muitos chegando após um dia de trabalho. Boas-vindas, apresentação da disciplina de Psicologia Social a estudantes de diferentes cursos da graduação: Biblioteconomia, Jornalismo, Relações Públicas, Publicidade e Propaganda, Arquivologia, Ciências Sociais, Filosofia, Design de Produto, Design Visual, História, Museologia. Turmas A e B.

Uma disciplina de Psicologia Social cuja orientação é conduzir o/a estudante a uma compreensão da "importância e necessidade da Psicologia Social, como conhecimento e análise dos problemas socioculturais que influem no comportamento do homem, no mundo atual" (Departamento de Psicologia Social e Institucional, 2020, p.1). Uma súmula abrangente para dar conta dessa diversidade de estudantes e seus interesses, tendo como objetivos estudar os diferentes paradigmas desse campo e discutir a função política da Psicologia, analisar a invenção da Psicologia Social desde uma perspectiva genealógica e abordar a sua constituição na América Latina e no Brasil, com ênfase na discussão sobre

\footnotetext{
${ }^{1}$ Informações complementares:

As figuras apresentadas no manuscrito são montagens de imagens de alguns dos trabalhos desenvolvidos por estudantes da disciplina de Psicologia Social I na Universidade Federal do Rio Grande do Sul. Embora tais trabalhos tenham sido retirados de publicações dos estudantes nos fóruns do Ambiente Virtual de Aprendizagem, solicitei, também, por e-mail um consentimento declarado em relação ao uso das imagens.
}

direitos humanos (Departamento de Psicologia Social e Institucional, 2020).

Um plano de ensino presencial, com seus conteúdos distribuídos ao longo de 18 semanas. Entretanto, o que ninguém naquelas salas de aulas imaginava é que, aproximadamente 10 dias após o início do ano letivo, seríamos surpreendidos por um e-mail vindo do Gabinete da Reitoria: as atividades presenciais da universidade estavam suspensas por 30 dias em função da pandemia do novo coronavírus (SARS-Cov-2) e da doença provocada por ele (COVID-19). Com o crescimento do número de pessoas infectadas e mortas em decorrência da Covid-19, essa suspensão foi sendo prorrogada mês após mês, até que, em meio a acirradas reuniões do Conselho Universitário, foi aprovada a controversa proposta do Ensino Remoto Emergencial (ERE), elaborada pela Pró-Reitoria de Graduação (PROGRAD) da Universidade Federal do Rio Grande do Sul.

O objetivo deste artigo é o de refletir sobre as experiências construídas ao longo desse semestre de ensino remoto na disciplina de Psicologia Social. A adaptação do plano da disciplina à modalidade emergencial buscou construir, junto aos/às estudantes, uma pedagogia engajada, que, como nos diz bell hooks (2020), "tem por objetivo recuperar a vontade dos estudantes de pensar e a vontade de alcançar a total autorrealização" (p.33). Essa pedagogia engajada era uma aposta em manter os/as estudantes engajados/as com a 
universidade e motivados/as para o semestre letivo, apesar de todas as dificuldades impostas pela pandemia, muito mais do que a preocupação com os conteúdos obrigatórios de uma ementa.

Inspirado no livro "Ensinando pensamento crítico", de bell hooks (2020), apresento e reflito sobre essas experiências, nas quais fui acompanhado também por estagiários/as de docência, a partir de três ensinamentos: a pandemia não é democrática - a negação do direito à educação; entendendo o ERE e os limites da aula expositiva - conversação e compartilhamento de histórias; aprendizagem colaborativa online, comunidade de aprendizagem e pensamento crítico.

\section{Ensinamento 1: a pandemia não é democrática - a negação do direito à educação}

Ainda nas primeiras notícias nos diferentes veículos de comunicação, afirmava-se, talvez no intuito de engajar as pessoas nos cuidados preventivos ou para enublar as reais consequências que seguiriam após a transmissão comunitária, que o coronavírus era democrático: atingia a todos/as, ricos/as e pobres, brancos/as e negros/as, sem qualquer tipo de distinção. Em Porto Alegre/RS, assim como em outras cidades país afora, o vírus chegou por intermédio de pessoas que viajaram para o exterior, para países como Itália ou China, o que revela o poder econômico das primeiras pessoas infectadas. Entretanto, uma das primeiras pessoas que morreram em decorrência do coronavírus no Brasil foi uma mulher, negra, moradora de periferia, empregada doméstica, cujos patrões haviam voltado há pouco de uma viagem para a Europa. $\mathrm{O}$ vírus, na sua materialidade biológica, pode até ser democrático, mas as suas condições de proliferação e consequências não o são. No Brasil, a pandemia atinge de forma desigual a população negra, periférica e vulnerável.

Os efeitos sentidos nos contextos social, econômico e político em nosso país chegaram como pautas importantes de discussão no campo da educação. Poderiam as escolas e universidades simplesmente suspender o calendário letivo até o retorno de uma normalidade? A rede privada de educação respondeu prontamente à demanda da sociedade pela continuidade das aulas. Desde março, instituições de ensino superior privadas, como as pertencentes aos grupos Kroton, Estácio e Unip, e as representadas pelas Pontifícias Universidades Católicas do país, definiram retorno às aulas mediado por tecnologias (Arruda, 2020).

Em nossa universidade, assim como em outras universidades federais, o retorno às aulas não ocorreu sem resistências. Considerando os avanços, ainda incipientes, promovidos pelo maior acesso ao ensino superior, principalmente através das ações afirmativas implementadas inicialmente com as cotas sociais e raciais, e também as grandes dificuldades de permanência na universidade de grupos de estudantes trabalhadores, indígenas e negros/as, questionaram-se os processos de exclusão e a negação do direito à educação que tais estudantes sofreriam com a oferta de uma modalidade de ensino remoto.

A quase inexistência de políticas públicas efetivas para a permanência dos/as estudantes na universidade fica evidente nas dificuldades vivenciadas cotidianamente por eles: condições de moradia, deslocamento, alimentação, sustento próprio, aquisição de materiais necessários aos processos de ensino e aprendizagem, dentre outros (Conselho da Unidade do Instituto de Psicologia, 2020). Tais fatores ficaram ainda mais visíveis no contexto excepcional da pandemia, somando-se o acesso à internet $\mathrm{e} o$ borramento das fronteiras entre os espaços doméstico, laboral, educacional e de lazer, efeitos do trabalho e ensino remotos (para aqueles/as que puderam permanecer em suas casas trabalhando e estudando). Tínhamos, portanto, a complexa tarefa de considerar que

Ao mesmo tempo em que a pandemia motiva a implementação de estratégias de ensino remoto, coloca em relevo os indicadores da profunda desigualdade racial e social que vivemos no Brasil, evidenciando as dificuldades de 
produção de relações de ensino/aprendizagem que possam contemplar igualitariamente o conjunto de estudantes. Neste sentido, entendemos que uma universidade autônoma, pública e democrática não pode desconsiderar o impacto dos indicadores da pandemia em sua comunidade acadêmica e propor um retorno às atividades de ensino no formato de Ensino Remoto Emergencial (ERE) sem prover a todas/os discentes as condições necessárias para participar deste novo "ecossistema educacional" (segundo a definição de ERE proposta pela PROGRAD) (Conselho da Unidade do Instituto de Psicologia, 2020, p.1).

Ou seja, ao mesmo tempo que a pandemia nos convocava a implementar estratégias de ensino remoto, ela também colocava em relevo aspectos da profunda desigualdade racial e social vividas no Brasil. Por isso, a universidade pública precisava se preocupar em criar as condições necessárias para essa modalidade de ensino, diminuindo os efeitos nefastos dessa desigualdade nas relações de ensino e aprendizagem.

Entretanto, com o inevitável retorno às aulas na modalidade remota, vivemos aquilo que temíamos: diminuição do número de estudantes matriculados/as (nas duas turmas de Psicologia Social, aproximadamente 20 estudantes cancelaram a matrícula); estudantes que, embora matriculados/as, não conseguiram concluir as disciplinas (nas duas turmas que acompanhei, em torno de 10 estudantes não concluíram, apesar de todos os esforços de contato com os mesmos); dificuldades de professores/as e estudantes com as nuances dessa modalidade de ensino, incluindo o conhecimento de ferramentas e plataformas digitais; as desigualdades nas condições de moradia e isolamento social influenciaram diretamente na construção de aprendizados; dentre outros.

Como afirmam Gomes, Oliveira e Sá, Vázquez-Justo, e Costa-Lobo (2020), “num jogo de espelhos, saúde e educação se miram: ambas refletem as desigualdades sociais e para elas contribuem; uma reforça as desigualdades da outra" (p. 5). Assim como ocorre em outros setores, espera-se da educação a recuperação do tempo perdido, sem considerar as condições físicas e de saúde mental dos atores educacionais. Professores e estudantes, que lidaram bem ou mal com as novas tecnologias, tiveram que administrar seu tempo, espaço e capacidades de estudar, acumulando tarefas intermináveis frente ao computador (Gomes, Oliveira e Sá, Vázquez-Justo, \& Costa-Lobo, 2020).

Mas, e esses/as 30 estudantes que se perderam nas malhas remotas do ensino? Estudantes mães que tiveram que se desdobrar entre seu trabalho formal, trabalhos domésticos e cuidado com os/as filhos/as? Estudantes trabalhadores/as que seguiram com sua rotina diária de horas entre ir e vir nos transportes públicos? Estudantes indígenas, negros/as, moradores/as de periferia sem acesso à internet ou a um computador pessoal que lhes oportunizasse o acompanhamento das aulas? $\mathrm{Ou}$ estudantes que simplesmente não conseguiram se adaptar a essa modalidade de ensino e que se sentiram cada vez mais ansiosos/as frente à pandemia e fracassados/as frente ao insucesso acadêmico? Não sabemos. O que sabemos é que o ERE tem como um de seus efeitos a negação do direito à educação para todos/as e que, como reflete Judith Butler (2020), somos testemunhas da rapidez com que a desigualdade radical encontra formas de reprodução e fortalecimento de seus poderes dentro das zonas pandêmicas.

\section{Ensinamento 2: entendendo o ERE e os limites da aula expositiva - conversação e compartilhamento de histórias}

Tendo como pano de fundo o contexto da pandemia e as críticas atribuídas em relação à proposta do ERE, passamos a busca pela compreensão do que seria esse ensino remoto e como poderíamos, com os/as estudantes que conseguissem acompanhar a disciplina, construir um espaço de aprendizagem significativa. A necessidade de utilizar 
Tecnologias Digitais de Informação e Comunicação (TDIC) gerou muitas controvérsias e confundiu professores/as, que acabaram concebendo o ensino remoto como sinônimo de Educação à Distância $(\mathrm{EaD})$.

O decreto $n^{\circ}$ 9057/2017 define que a $\mathrm{EaD}$ é uma modalidade educacional na qual a mediação dos processos de ensino e aprendizagem ocorre através da utilização de meios e tecnologias da informação e comunicação, com políticas de acesso, avaliação e acompanhamento compatíveis, e que permita aos/às estudantes o acesso aos materiais didático-pedagógicos em diferentes tempos e espaços (Decreto n. 9057, 2017). A $\mathrm{EaD}$, portanto, envolve um planejamento anterior e se preocupa com o desenvolvimento de produtos com qualidade pedagógica e estética (Maia \& Mattar, 2008).

Já a educação remota emergencial, conforme afirmam Hodges, Moore, Lockee, Trust e Bond (2020) e Arruda (2020), é uma mudança temporária, envolvendo soluções de ensino remotas para aulas que haviam sido previamente planejadas como presenciais. $\mathrm{O}$ ensino remoto pode mesclar momentos síncronos e assíncronos. No primeiro caso, a educação remota pode ser apresentada em tempo semelhante à educação presencial, com os conteúdos e programação divididos por semanas de aulas e encontros online com os/as estudantes. Nos momentos assíncronos, temos a possibilidade de utilizar inúmeras ferramentas digitais para a gravação de conteúdos, que poderão ser acessados pelos/as estudantes em qualquer tempo e espaço (Arruda, 2020).

Cabe destacar que se formou, em nosso departamento, um grupo de professores/as das disciplinas de psicologia social. Através deste grupo, compartilhamos conteúdos e materiais como vídeos e podcasts que poderiam ser utilizados como ferramentas metodológicas para o desenvolvimento do semestre remoto. No ensinamento sobre colaboração, escrito com Ron Scapp, bell hooks (2020) se refere à importância de colaborar com diferentes pensadores na construção de uma compreensão mais ampla das dinâmicas de raça, gênero e classe, o que nos moveria para espaços além daqueles unidimensionais de pensamento. A autora, ao referir-se a ela e seu parceiro intelectual Ron, afirma que o contínuo diálogo "é um esforço constante para manter a consciência crítica sobre o que fazemos, como fazemos e por quê" (hooks, 2020, p. 74). Neste sentido, posso considerar que o grupo de professoras/es exerceu não apenas uma função de apoio pedagógico, mas também de apoio emocional num momento em que todas/os estávamos tentando compreender o que e como fazer. No isolamento de nossas casas, as reuniões departamentais com todo o corpo docente, para além dos protocolos, também operou como dispositivo de diálogo crítico e contínuo sobre nossas angústias e reinvenções didático-pedagógicas, bem como sobre o papel da universidade junto àquelas e àqueles a quem, mais uma vez, estávamos negando o seu direito à educação.

$\mathrm{Na}$ reorganização da disciplina de Psicologia Social, disponibilizamos aos/às estudantes no Ambiente Virtual de Aprendizagem (AVA) uma série de materiais escritos e audiovisuais, conforme os conteúdos dos dois módulos da disciplina - Módulo I: Constituição da Psicologia Social; e Módulo II: Temas Contemporâneos em Psicologia Social (Departamento de Psicologia Social e Institucional, 2020). Para abordar os conteúdos do primeiro módulo (constituição histórica e epistemológica do campo; diferentes paradigmas em Psicologia Social; a invenção da Psicologia Social desde uma perspectiva genealógica; e Psicologia Social no Brasil e na América Latina), gravamos e editamos vídeoaulas, podcasts, bem como disponibilizamos textos e resumos dos conteúdos. No módulo II (no qual abordamos temas como relações étnico-raciais; gênero, sexualidade e direitos humanos; políticas das infâncias e juventudes; novas tecnologias, subjetividade e trabalho; medicalização da vida), além dos materiais já citados, também gravamos entrevistas sobre as temáticas com colegas de departamento e de outros cursos e universidades. 
Todo esse escopo didático-pedagógico consistiu no que chamamos de momentos assíncronos da disciplina. Momentos que permitiram às/aos estudantes o estudo dos conteúdos da disciplina em diferentes tempos e espaços. Nos horários de aulas com as duas turmas, propomos os "pontos de encontro": momentos síncronos, online, para sanar dúvidas sobre os conteúdos estudados e conversar. Muitas vezes, simplesmente conversamos: sobre a vida, sobre os medos e ansiedades em relação à pandemia, sobre o desânimo dos/as estudantes frente ao atual contexto político de nosso país. Contamos e compartilhamos histórias. Nos ensinamentos de bell hooks (2020), aprendemos que contar histórias é uma das formas que temos para começar o processo de construção de comunidade que, no nosso caso, era uma comunidade de aprendizagem. Conforme a autora, as salas de aulas foram transformadas significativamente "pela insistência do movimento feminista contemporâneo em que o 'pessoal é político', em que experiência deve ser tão valorizada quanto as informações factuais, e em que há de fato espaço no processo de aprendizagem para contar histórias pessoais" (hooks, 2020, p. 97).

Nesse sentido, evitamos as aulas expositivas nos encontros síncronos, concordando com Bates (2017), ao afirmar que as aulas expositivas tendem a se concentrar mais na transmissão de informações, em detrimento das conversações e discussões entre professores/as e estudantes. E, seguindo o dilema de bell hooks (2020), sobre palestrar ou não, quando começarmos a de fato levar a sério os processos de ensino e de aprendizado, "a palestra longa já não ocupará o espaço proeminente que tem ocupado. Porque, de várias maneiras, a palestra é o momento de ensino que mais promove passividade $\mathrm{e}$ desencoraja a participação de aprendizes" (p. 110). Os pontos de encontro, dessa forma, tinham como objetivo a construção de vínculos através de conversações, de diálogos engajados, nos quais estudantes e professores/as estão dando e recebendo, construindo um aprendizado genuíno (hooks,
2020), sempre mútuo. Ao escolher e nutrir o diálogo, nos envolvemos mutuamente na parceria de aprendizagem, na aventura de construir pensamento crítico e de romper com "a noção de que adquirir conhecimento é particular, individualista e competitiva" (hooks, 2020, p. 81). E foi assim que, mais preocupados com o engajamento dos estudantes do que com os conteúdos programáticos e avaliações, aprendemos de forma colaborativa, engajada e fomentando uma sensação de pertencimento - a uma comunidade de aprendizagem.

\section{Ensinamento 3: aprendizagem colaborativa online, comunidade de aprendizagem e pensamento crítico}

Em um dos cursos promovidos pela escola de desenvolvimentos dos servidores de nossa universidade, bem como através dos materiais elaborados pelos profissionais da Secretaria de Educação à Distância (SEAD), identificamos que a aprendizagem colaborativa online, que ocorre principalmente através da atividade de fóruns de discussão no AVA, era o mote das nossas propostas de trabalhos avaliativos nesse semestre remoto. Em uma comunidade de conhecimento (Bates, 2017), ou comunidade de aprendizagem (hooks, 2020), o/a professor/a é mais do que um mediador na construção do conhecimento: ele/a busca apresentar experiências (contando histórias, dialogando) e informações (conjunto de materiais disponibilizados no AVA) para disparar nos grupos de estudantes a geração de ideias, a sua organização e uma convergência intelectual (Bates, 2017), por temas de interesse ou escolhas teóricas.

No primeiro módulo da disciplina de Psicologia Social, propomos como trabalho avaliativo a construção de um mapa conceitual. Resumidamente, o mapa conceitual é uma ferramenta de geração e organização de ideias, conforme proposto por Bates (2017). Trata-se de uma representação gráfica de um conjunto de conhecimentos e conceitos construídos, evidenciando a relação entre eles. Para a criação do mapa conceitual foram indicados alguns softwares e aplicativos, ou poderia ser 
realizado de forma manual e depois fotografado ou escaneado para ser postado no fórum de discussão criado no AVA.

No decorrer das seis primeiras semanas de aula, junto com as discussões dos conteúdos e conversas cotidianas, abríamos espaço para a troca de ideias sobre a construção dos mapas. Assim, percebemos o quanto os/as colegas conseguiam trocar informações e promover uma ajuda mútua com os trabalhos, embora a avaliação fosse individual. Alguns/as estudantes optaram por elaborar um mapa mais tradicional, abordando e relacionando os principais conceitos e ideias do primeiro módulo, como pode-se observar nos mapas das figuras 1 e 2. Outros, contudo, sentiram-se mais motivados a não detalhar tanto os conceitos, mas relacionar o campo da Psicologia Social com seus trabalhos, áreas de formação e temas de pesquisas.

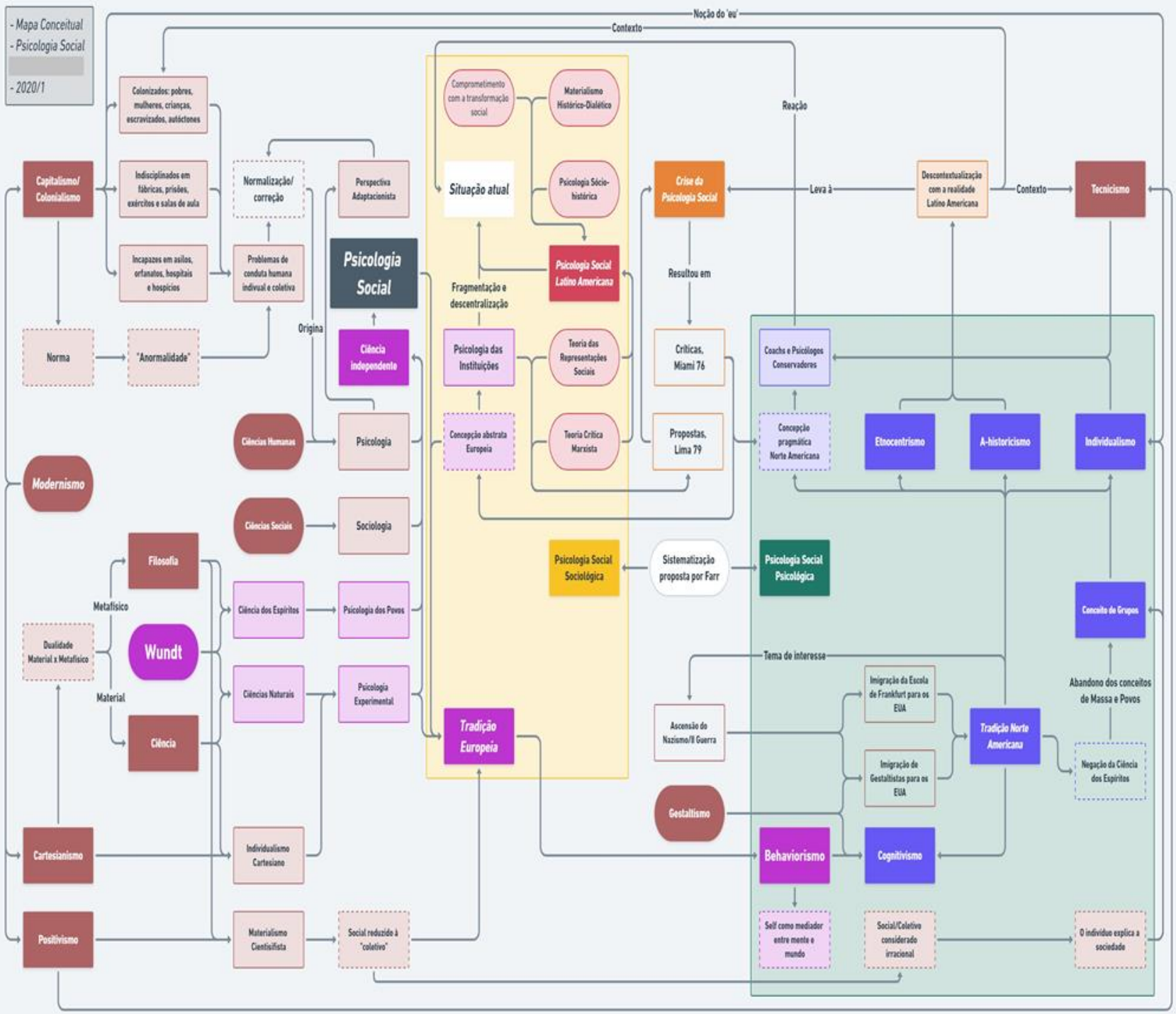

Figura 1. Construção dos Mapas Conceituais ${ }^{2}$

Nota. elaborado pelo autor a partir de trabalhos publicados no AVA

${ }^{2}$ Imagem apliada no final do arquivo. 


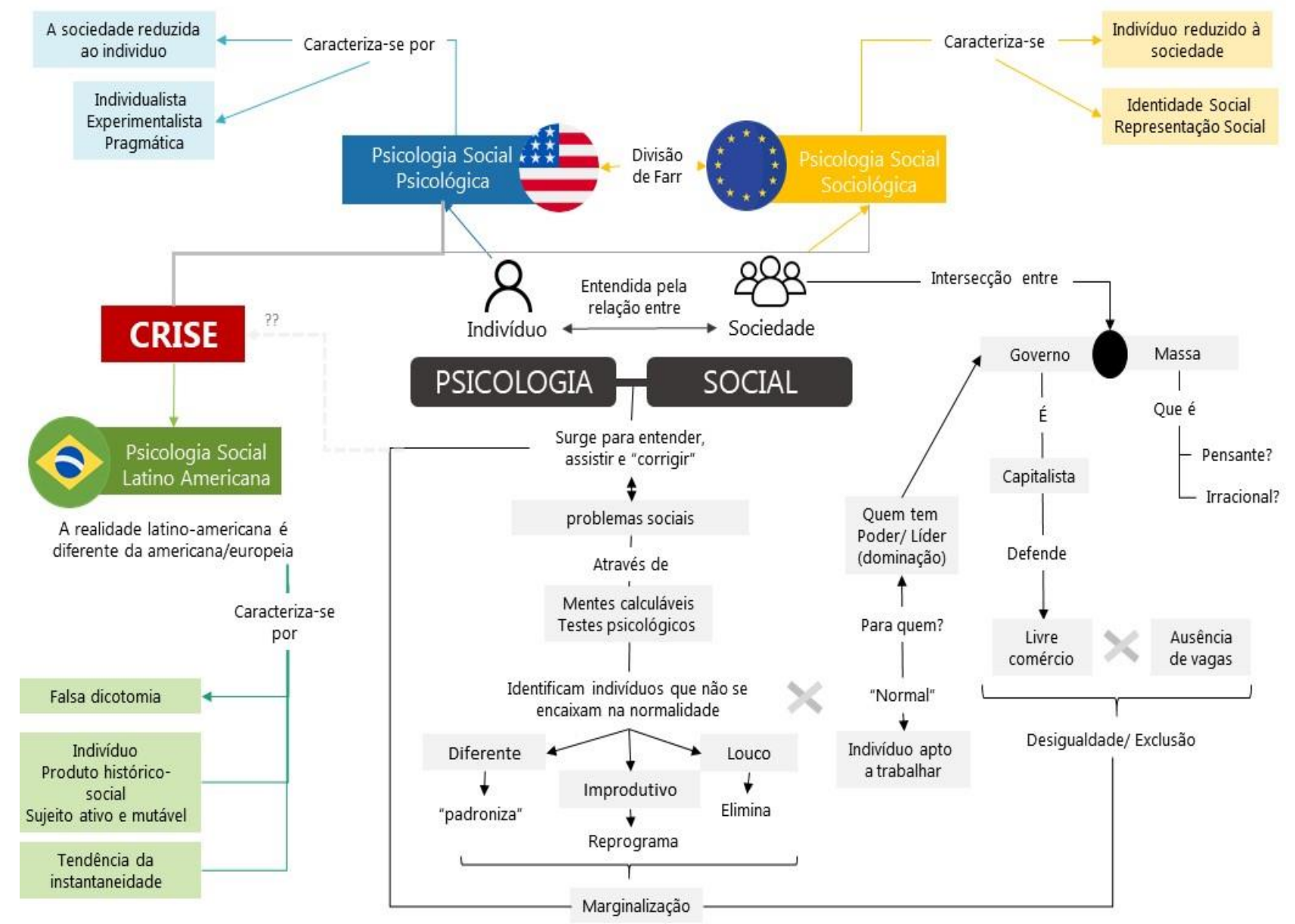

Figura 2. Construção dos Mapas Conceituais

Nota. elaborado pelo autor a partir de trabalhos publicados no AVA

Essa segunda possibilidade abriu a nossa discussão para diferentes perspectivas e temas: relações entre a psicologia social e as áreas de publicidade e propaganda, design de produto, arquivologia e jornalismo; e reflexões sobre o livro "1984", de George Orwell, filmes sobre a ditadura militar na Argentina e Uruguai, notícias jornalísticas sobre o caso do sequestro do ônibus 174, dentre outros, a partir de conceitos e noções discutidas na primeira parte da disciplina. Dois exemplos dessa forma de construir os mapas conceituais podem ser vislumbrados nas figuras 3 e 4 . 


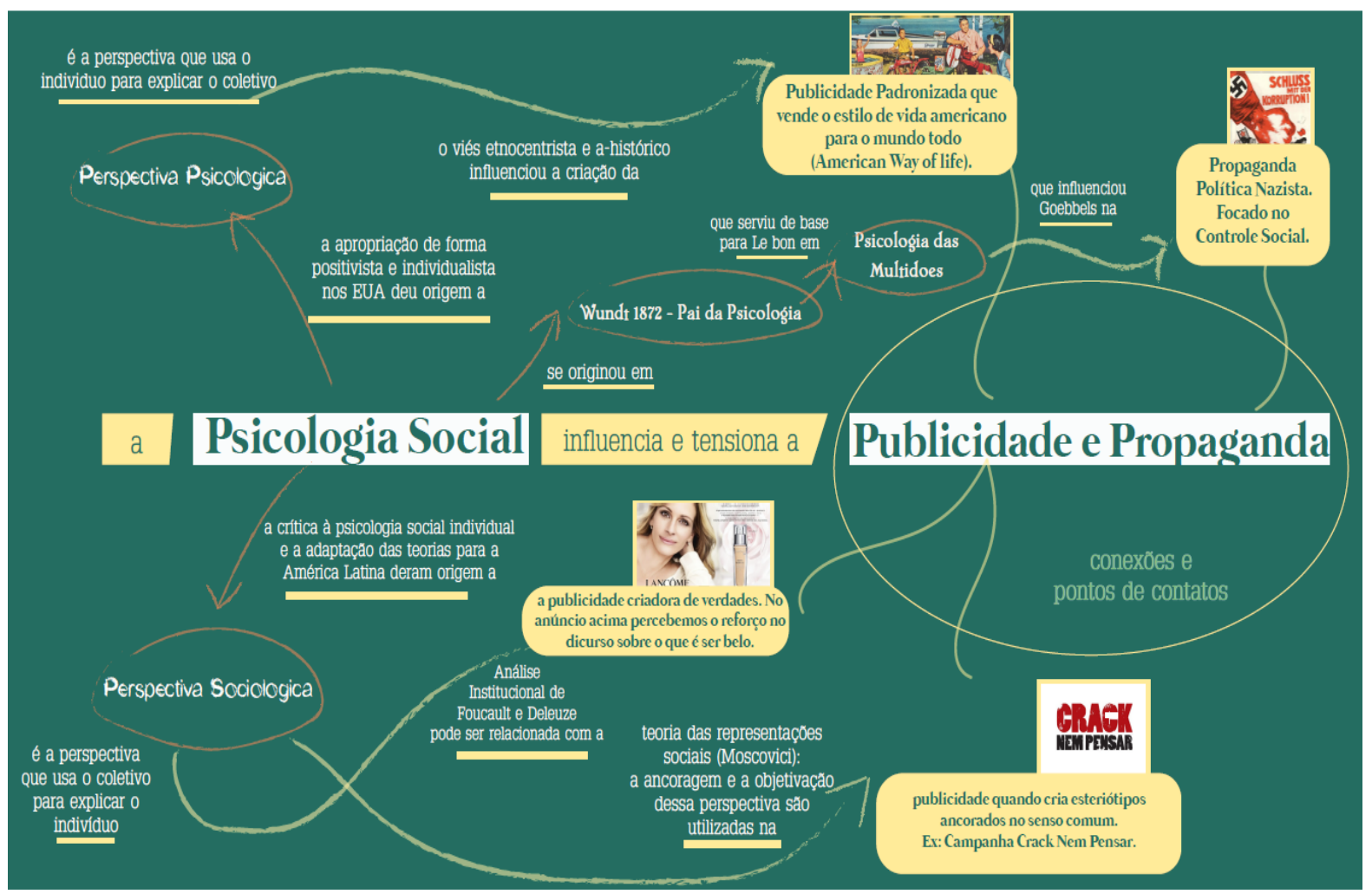

Figura 3. Mapas Conceituais - relações da Psicologia Social e o curso de Publicidade e Propaganda ${ }^{3}$ Nota. elaborado pelo autor a partir de trabalhos publicados no AVA

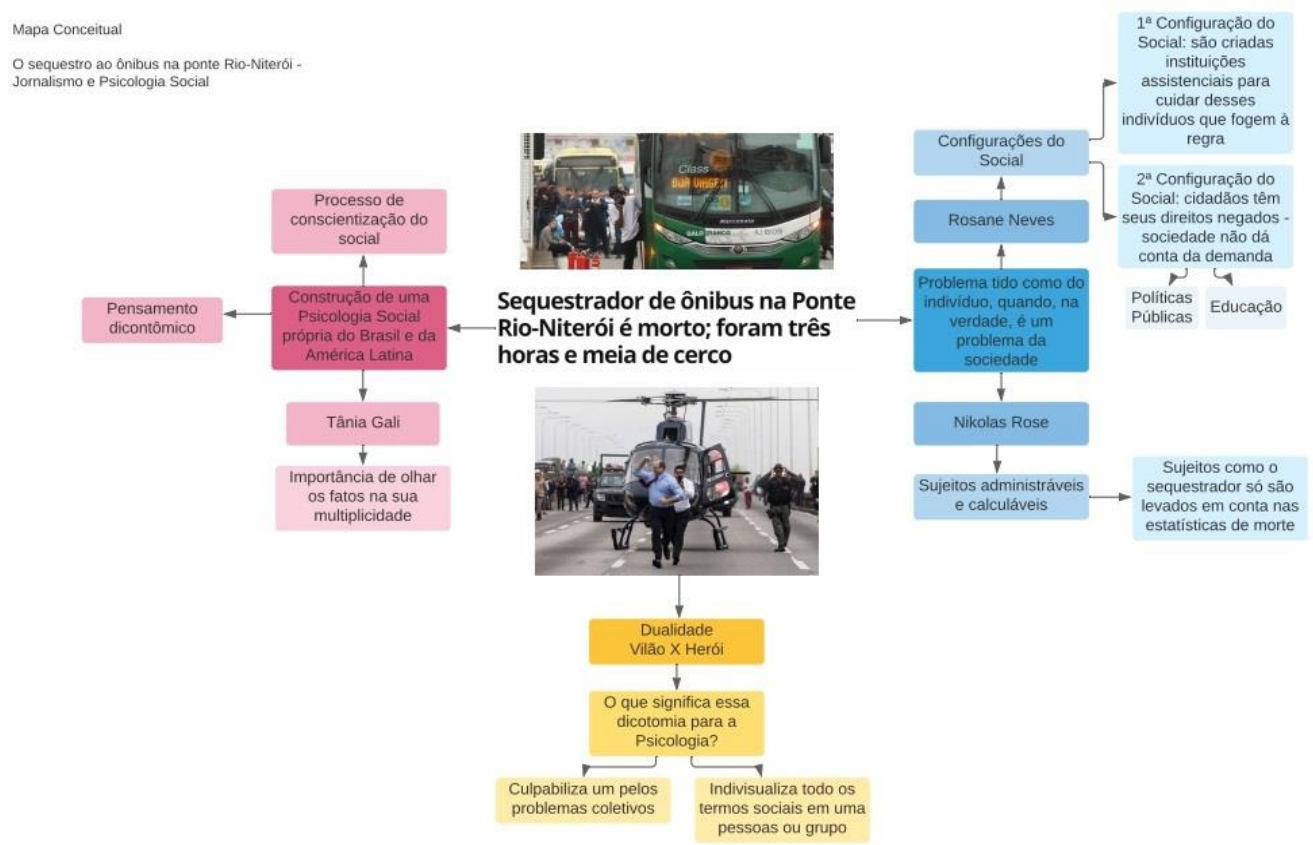

"Na manhă da terça-feira, 20 de agosto de 2019, Willian Augusto da Silva, 20 anos, tomou o ônibus linha 2520, direçāo São Gonçalo - Estácio (RJ). Ass 5h26, 16 minutos após entrar

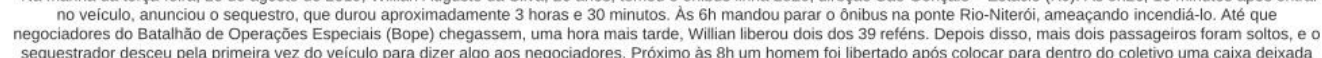
pela policia do lado de fora. Mais uma refém sai do ônibus, e Willian joga na rua uma outra caixa. As 9h04 um atirador de elite de elite do Bope acerta 6 tiros no sequestrador. A sua morte é confirmada 12 minutos depois pela Policia e Witzel, Governador do Rio de Janeiro, comemora. Willian portava uma arma de mentira e ameaçava incendiar o ônibus com artificios improvisados feitos de garrafa PET com gasolina dentro palhados pela cabine. Nenhum dos reféns se machucou.
Mais infos: https:/lg1.globo.com/rifrio-de-janeiro/noticia/2019/08/20/homem-armado-ameaca-passageiros-em-onibus-na-ponte-rio-niteroi.ghtm!

Figura 4. Mapas Conceituais - Jornalismo e Psicologia Social ${ }^{4}$

Nota. elaborado pelo autor a partir de trabalhos publicados no AVA

\footnotetext{
${ }^{3}$ Imagem apliada no final do arquivo.

${ }^{4}$ Imagem apliada no final do arquivo.
} 
$\mathrm{Na}$ busca por autonomia na produção de ideias e de uma pedagogia engajada pautada na conversação e construção do pensamento crítico (hooks, 2020), a criação desses trabalhos fomentou ainda mais a participação dos/as estudantes na segunda parte da disciplina. No segundo módulo, para cada tema (relações étnico-raciais; gênero, sexualidade e direitos humanos; políticas das infâncias e juventudes e novas tecnologias; subjetividade trabalho e medicalização da vida), sugerimos leituras, vídeos e/ou podcasts para que os/as estudantes pudessem se aproximar da temática. A partir da compreensão dos/as estudantes sobre os textos e materiais disponibilizados, cada estudante, dupla ou trio foi convidado a construir um material informativo e/ou artístico sobre o tema. Esse material poderia ser um vídeo, um podcast, um fôlder, um cartaz, utilização de fotografias autorais, dentre tantos outros. A construção era livre. Um trabalho de imaginação. Imaginar é, segundo bell hooks (2020), uma das potentes formas de resistência, pois "o que não podemos imaginar não pode vir a ser" (p. 103).

Para aqueles e aquelas não afeitos a esse tipo de produção, foi dada a escolha de uma produção textual. A partir de grupos de trabalho que se constituíram das preferências dos/as estudantes pelos temas elencados, os pontos de encontro tornaram-se comunidades de aprendizagem (hooks, 2020), nas quais, ao invés de apenas consumir informações e regurgita-las nos momentos apropriados, os/as estudantes se engajaram num processo interativo e, com a mente aberta, discutiram e propuseram trabalhos muito significativos, para si mesmos e para o coletivo que havia se constituído. Com a orientação do professor e estagiários/as de docência, convergiram intelectualmente (Bates, 2017) formando duplas ou trios a partir dos interesses comuns e das habilidades distintas e complementares na produção do material.

$\mathrm{Na}$ imagem 5 temos os exemplos de um material popularmente conhecido como "lambe-lambe", cujas autoras nomearam de intervenção urbana transfeminista. No debate sobre medicalização, subjetividade e trabalho, temos um trabalho realizado com a técnica de colagem. Outros tantos foram produzidos, tais como: podcasts (representação LGBT+ na mídia televisiva; racismo na NBA; o trabalho remoto em tempos de distanciamento social); vídeos (sobre como psicoterapeutas não devem tratar o público LGBT+; sofrimento e medicalização na sociedade capitalista); cartilhas, folders, flyers e cartazes (adoção; economia solidária; criatividade e produtividade na pandemia; como combater o racismo - um manual para pessoas brancas); dentre outros. 


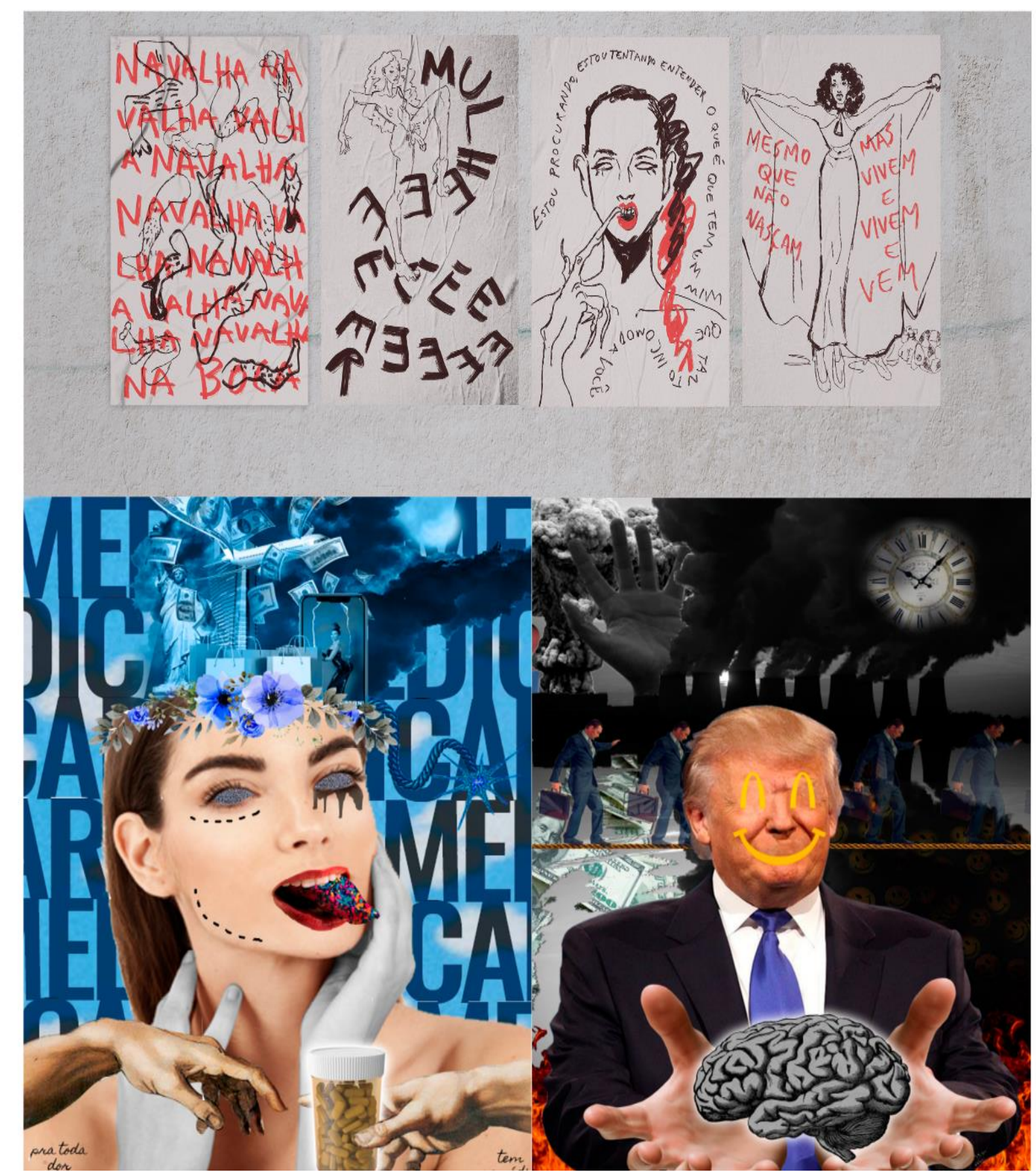

Figura 5. Materiais informativos elou artísticos sobre temáticas contemporâneas em Psicologia Social

Nota. elaborado pelo autor a partir de trabalhos publicados no AVA

Todos esses trabalhos produzidos pelos/as estudantes foram o resultado de encontros de conversação, da tentativa de construir uma comunidade virtual de aprendizado, do encontro entre professor e estagiários/as de docência e duas turmas dispostas a interagir e aprender uns com os outros. O aprendizado genuíno, assim como o amor, é sempre mútuo. $\mathrm{O}$ amor na sala de aula, nos diz bel hooks (2020), “estabelece uma base para o aprendizado que acolhe e empodera todo mundo" (p. 239). Conforme a autora, o amor é uma combinação de cuidado, comprometimento, responsabilidade, respeito, conhecimento e confiança. E, "quando esses princípios básicos do amor formam a base da interação professor-estudante, a busca mútua por conhecimento cria as condições para um 
aprendizado ideal" (hooks, p. 239). Em tempos de pandemia e distanciamento social, o que todos/as nós precisávamos era de amor.

\section{Considerações Finais - Efeitos e Desafios de uma Pandemia que continua}

Essa proposta de ensino e de aprendizagem em uma disciplina de Psicologia Social surgiu da necessidade de repensarmos criticamente a função da educação nesse contexto tão turbulento em que vivemos. Assim como compartilhamos e construímos histórias com nossos/as estudantes, consideramos importante compartilhar tais ensinamentos que essas experiências nos oportunizaram. Como buscamos demonstrar através dos três ensinamentos discutidos, entendemos que a situação da pandemia e do distanciamento social nos convocou a repensar o lugar das aulas expositivas, propondo encontros de conversação, pensamento crítico e construção de uma comunidade de aprendizado.

Curiosamente, a SEAD, responsável pelos cursos à distância e apoio qualificado para a situação emergencial de semestre remoto, vem sofrendo ataques em sua estrutura e número de profissionais pela atual gestão da reitoria (aliás, gestão essa nomeada pelo presidente da república em detrimento da escolha da comunidade universitária, mesmo sendo questionáveis os parâmetros e pesos adotados para a eleição do/a reitor/a). Compartilhar nossas experiências com a disciplina de Psicologia Social no ERE, exitosas com aqueles e aquelas que conseguiram acompanhar a disciplina, é, também, uma forma de apoio aos nossos colegas que vem enfrentando uma precarização sem precedentes.

Acreditamos que temos, dentre outros, dois desafios centrais diante dessa modalidade emergencial de ensino. Primeiro, que a utilização das tecnologias digitais de informação e comunicação possibilitou a construção de aprendizagens significativas, ou genuínas, como diria bell hooks. Além disso, foi possível acompanhar, dialogar e pensar criticamente com os estudantes numa perspectiva de pedagogia engajada, com maior autonomia e participação dos estudantes. Afirmar isso não significa, de modo algum, negar o nosso desejo de estar com os/as estudantes, presencialmente, lutando por uma educação pública e de qualidade. Esse primeiro desafio consiste em como vamos nos apropriar dessas metodologias mais participativas no modelo presencial. Como incluir um/a estudante trabalhador/a em uma aula que não se propõe expositiva, mas dialogada?

O segundo desafio, que cabe a todos/as nós, é, em meio a tantos retrocessos e desinvestimentos nas políticas públicas de educação, manter, acompanhar e incluir estudantes que, por razões diversas, não conseguiram se vincular ao semestre remoto. Provavelmente as dificuldades vividas por esses/as estudantes já existissem, mas as condições sociais, culturais e econômicas que sustentam as desigualdades sociais se tornaram mais visíveis com a pandemia, e isso deve nos sensibilizar quando do retorno presencial das aulas. Que movimentos micropolíticos podemos fazer dentro dos departamentos e dos cursos para, além de ampliar o acesso, conseguirmos efetivamente trabalhar para a permanência dos/as estudantes? Na disciplina de Psicologia Social, talvez possamos incluir um tema contemporâneo: implicações psicossociais, saúde mental e direito à educação em tempos de pandemia.

Como nos diz Ailton Krenak, o nosso tempo é especialista em criar ausências. Ausência do sentido de viver, ou de estar na universidade nesses tempos pandêmicos. A pandemia, o ERE e todas as desigualdades intensificadas nesse período parecem $\mathrm{O}$ prenúncio do fim do mundo (o de um fim do mundo, do fim de alguns mundos - as interpretações podem ser muitas). E ecoam esse fim como uma possibilidade de fazer as pessoas desistirem dos seus sonhos e de seus direitos. Aceitando a provocação de Krenak, estaremos adiando o fim contando mais uma história, oportunizando espaços coletivos para construirmos e compartilharmos novas histórias. Dentro e fora da universidade. 


\section{Referências}

Arruda, E. P. (2020). Educação Remota Emergencial: elementos para políticas públicas na educação brasileira em tempos de Covid-19. EmRede - Revista de Educação à Distância, 7(1), 257-275. doi: 0000-0002-9201-6530

Bates, A. W. (2017). Educar na era digital: design, ensino e aprendizagem. São Paulo: Artesanato Educacional.

Butler, J. (2020). El capitalismo tiene sus límites. In Editorial: ASPO Aislamiento Social Preventivo y Obligatorio (Ed.), Sopa de Wuhan: pensamiento contemporáneo en tempos de pandemia (pp. 59-66). Buenos Aires: ASPO.

Conselho da Unidade do Instituto de Psicologia. (2020). Apreciação da Proposta de Regulamentação de Ensino Remoto Emergencial apresentada pela PROGRAD através do Ofício $n$. 025/PROGRAD/UFRGS. Porto Alegre: Autor.

Decreto n. 9057, de 25 de maio de 2017. Regulamenta o art. 80 da Lei $\mathrm{n}^{\circ}$ 9.394, de 20 de dezembro de 1996, que estabelece as diretrizes e bases da educação nacional. Recuperado de
http://www.planalto.gov.br/ccivil_03/Ato2 015-2018/2017/Decreto/D9057.htm

Departamento de Psicologia Social e Institucional. (2020). Plano de Ensino Psicologia Social I. Porto Alegre: Instituto de Psicologia, Departamento de Psicologia Social e Institucional.

Gomes, C. A., Oliveira e Sá, S., VázquezJusto, E., \& Costa-Lobo, C. (2020). A Covid-19 e o Direito à Educação. Revista Internacional de Educación para la Justicia Social, 9(3), 1-14. Recuperado de https://revistas.uam.es/riejs/article/view/12 176

Hodges, C. B., Moore, S., Lockee, B. B., Trust, T., \& Bond M. A. (2020). The difference between emergency remote teaching and online learning. EDUCAUSE Review. 27 mar. 2020. Recuperado de https://er.educause.edu/articles/2020/3/thedifference-between-emergency-remoteteaching-and-online-learning

hooks, b. (2020). Ensinando Pensamento Crítico: sabedoria prática. São Paulo: Elefante.

Maia, C., \& Mattar, J. (2008). ABC da EaD: a educação a distância hoje. São Paulo: Pearson Prentice Hall.

\section{Dados sobre o autor:}

- Moises Romanini: Psicólogo, graduado pela UFSM; Doutor em Psicologia Social e Institucional (UFRGS); Professor Adjunto do Departamento de Psicologia Social e Institucional da UFRGS; Atua na coordenação conjunta do Grupo de Pesquisa-Intervenção em Saúde Mental, Políticas Públicas e Cuidado em Rede (INTERVIRES/UFRGS).

\section{Agradecimentos:}

- Aos/ás estudantes das turmas A e B de Psicologia Social I da UFRGS (Semestre 2020/1), por terem tornado possível esse semestre, engajando-se em encontros apesar de todas as dificuldades enfrentadas durante a pandemia, tornando esse período mais leve e afetivo. À Amanda Rocha e ao Vincent Goulart, por terem me acompanhado, através de seus estágios de docência, com sensibilidade e criticidade, construindo vínculos e aprendizagens significativas com as turmas.

Declaração de Direito Autoral

A submissão de originais para este periódico implica na transferência, pelos autores, dos direitos de publicação impressa e digital. Os direitos autorais para os artigos publicados são do autor, com direitos do periódico sobre a primeira publicação. Os autores somente poderão utilizar os mesmos resultados em outras publicações indicando claramente este periódico como o meio da publicação original. Em virtude de sermos um periódico de acesso aberto, permite-se o uso gratuito dos artigos em aplicações educacionais e científicas desde que citada a fonte conforme a licença CC-BY da Creative Commons. 


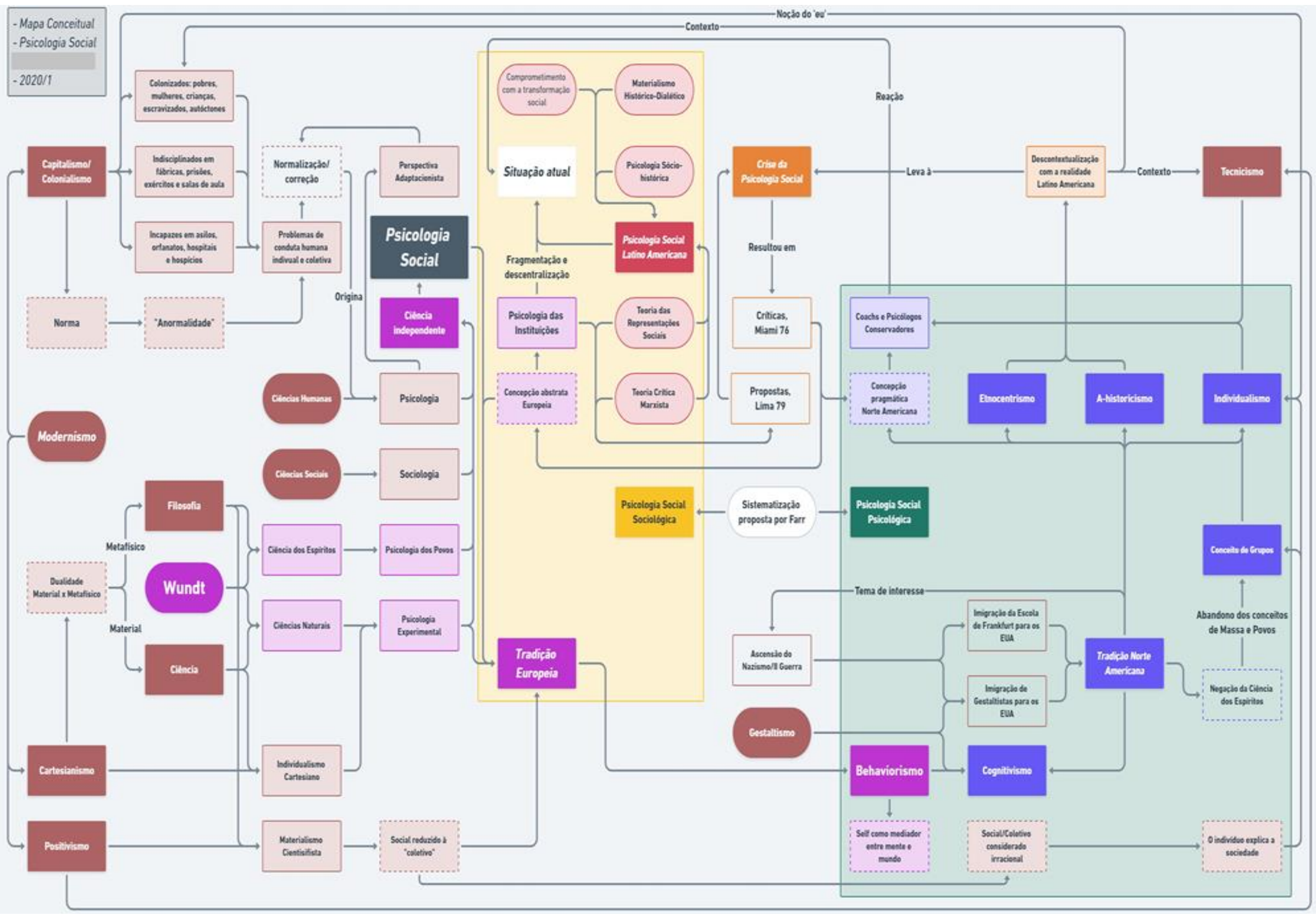


é a perspectiva que usa 0 individuo para explicar 0 coletivg

Perspectiva Psicologica

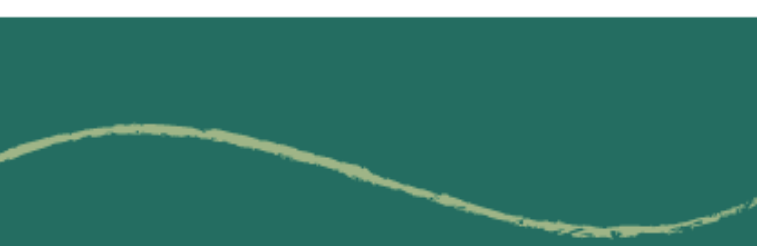
influenciou a criaçăo da

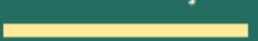

a apropriaçăo de forma positivista e individualista nos EUA deu origem a

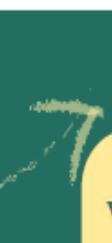

Publicidade Padronizada que vende o estilo de vida americano para o mundo todo (American Way of life).

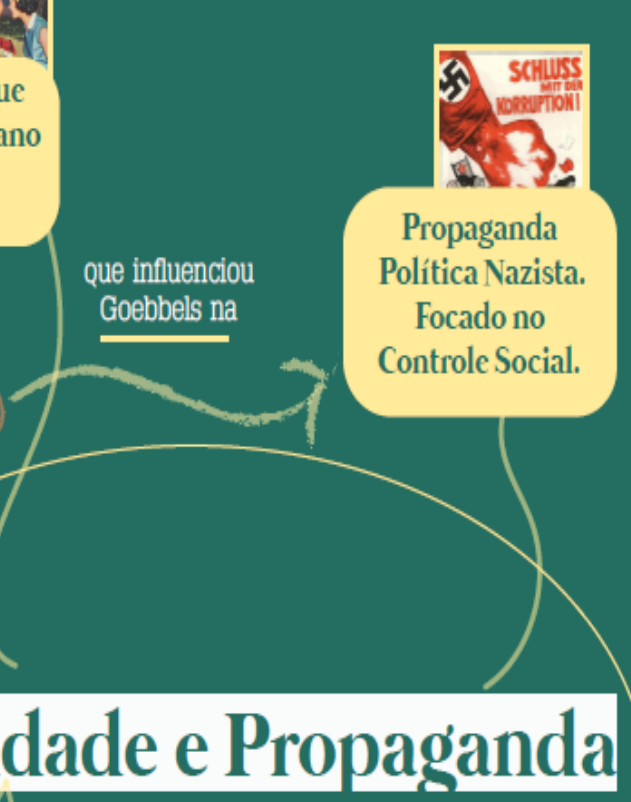

a Psicologia Social influencia e tensiona a

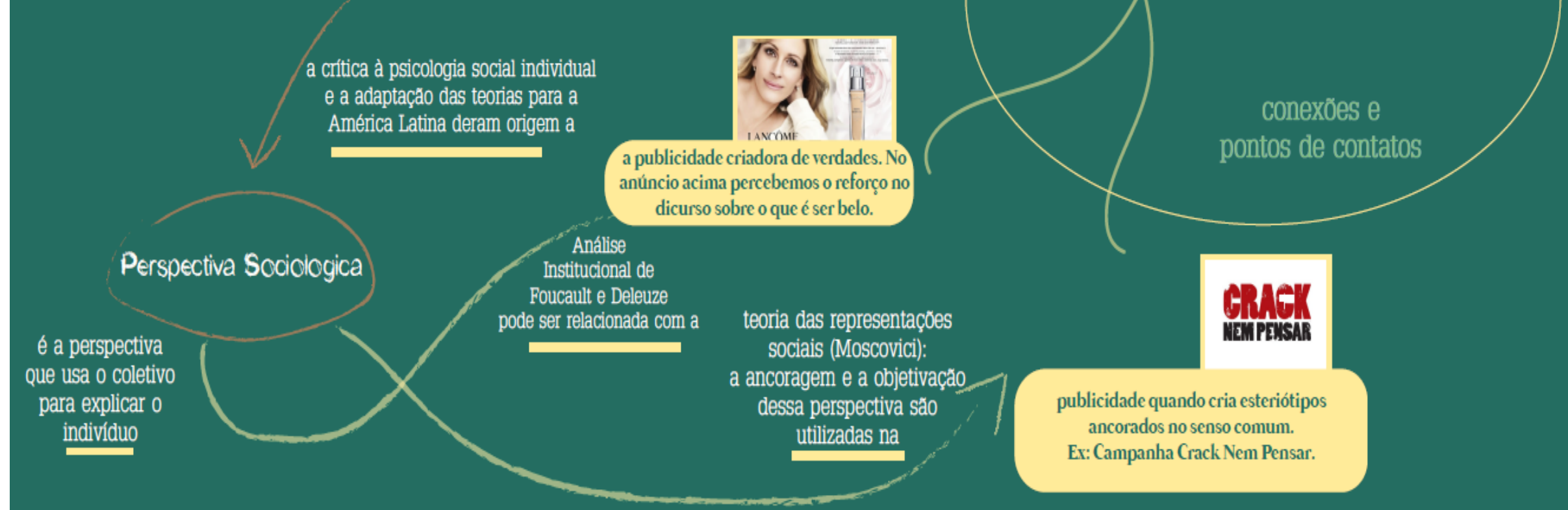




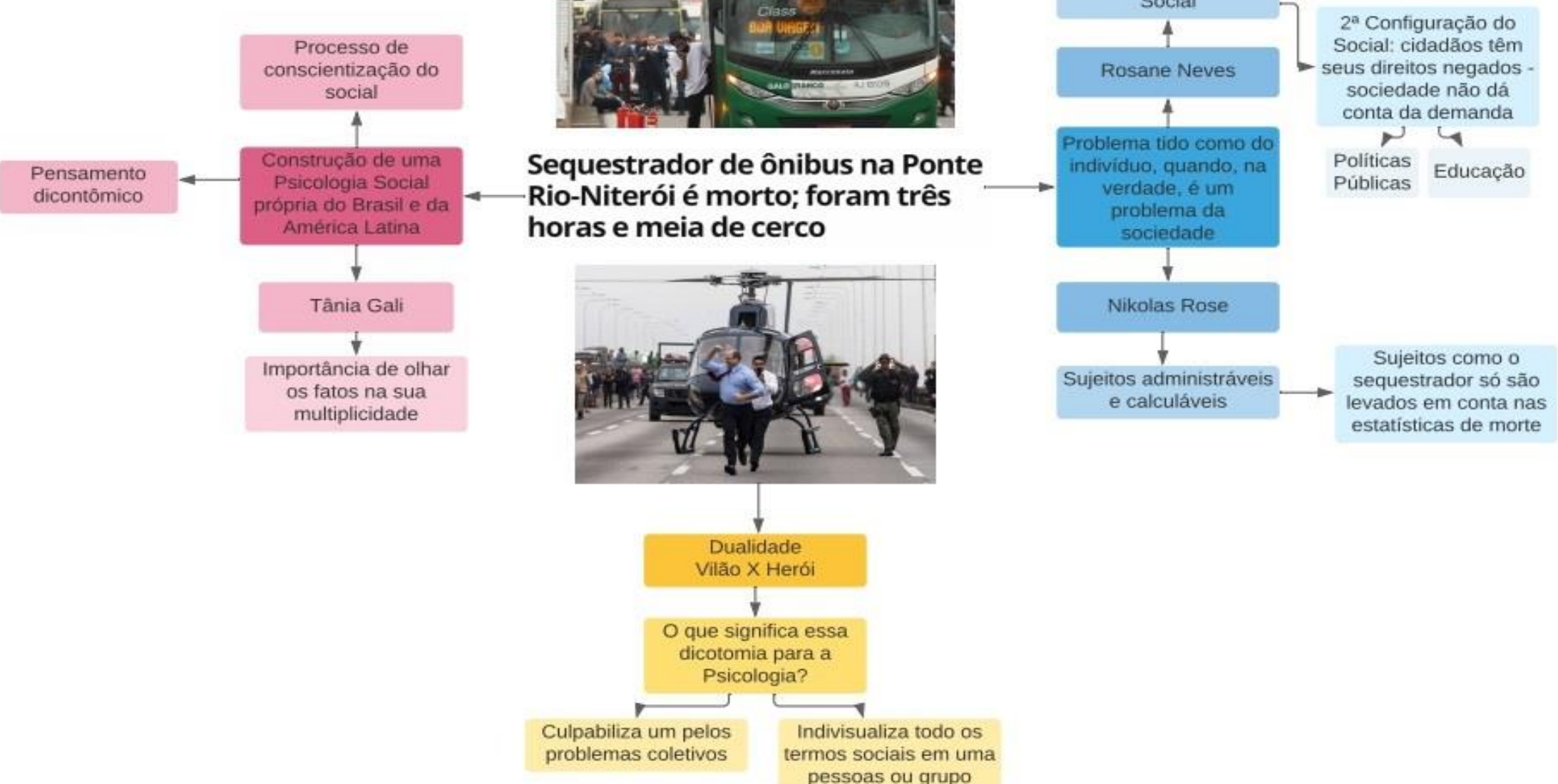

Configuração do Social: são criada instituiçōes

assistenciais para individuos que fogem à regra

Configuração do onta da demanda $\checkmark \quad 4$

Sequestrador de ônibus na Ponte io-Niterói é morto; foram três

*Na manhã da terça-feira, 20 de agosto de 2019, Willian Augusto da Silva, 20 anos, tomou o ônibus linha 2520, direçāo São Gonçalo - Estácio (RJ). Ás 5 h26, 16 minutos após entrar no veículo, anunciou o sequestro, que durou aproximadamente 3 horas e 30 minutos. As $6 \mathrm{~h}$ mandou parar o ônibus na ponte Rio-Niterói, ameaçando incendiá-lo. Até que negociadores do Batalhão de Operações Especiais (Bope) chegassem, uma hora mais tarde, Willian liberou dois dos 39 reféns. Depois disso, mais dois passageiros foram soltos, e o sequestrador desceu pela primeira vez do veículo para dizer algo aos negociadores. Próximo às $8 \mathrm{~h}$ um homem foi libertado após colocar para dentro do coletivo uma caixa deixada pela polícia do lado de fora. Mais uma refém sai do ônibus, e Willian joga na rua uma outra caixa. As 9h04 um atirador de elite de elite do Bope acerta 6 tiros no sequestrador. A sua morte é confirmada 12 minutos depois pela Polícia e Witzel, Governador do Rio de Janeiro, comemora. Willian portava uma arma de mentira e ameaçava incendiar o ônibus com artifícios improvisados feitos de garrafa PET com gasolina dentro palhados pela cabine. Nenhum dos reféns se machucou.

Mais infos: https://g1.globo.com/ri/rio-de-janeiro/noticia/2019/08/20/homem-armado-ameaca-passageiros-em-onibus-na-ponte-rio-niteroi.ghtm/ 